\title{
Protected Areas' Latent Functions and Social Consequences: A Case from Mount Hamiguitan, Philippines
}

\author{
Eva N. Mendoza ${ }^{1,}$, , Roy G. Ponce ${ }^{2}$, Sheryl Mae A. Soria ${ }^{1}$ and Victor B. Amoroso ${ }^{1}$ \\ 1 Central Mindanao University, University Town, Musuan, Bukidnon, Philippines \\ 2 Davao Oriental State College, Mati City, Davao Oriental \\ * Corresponding author: evamendoza@cmu.edu.ph; +639057786511
}

\begin{abstract}
While protected areas (PAs) are established primarily for biological diversity conservation and provision of ecological services, social dimensions comes into play. This paper extends the discourse on PAs' impact to local communities by focusing on the latent functions and social consequences utilizing Robert Merton's Functional Analysis. Based on in-depth interviews among community leaders and elders, and forest custodians around Mount Hamiguitan, a UNESCO World Heritage Site, it is revealed that establishment of PAs entails varied consequences beyond what are being intended and manifested. While communities availed of some latent benefits from the declaration of the PA, they also have responses that limit the success of conservation initiatives. Hence, forest protection is a complex social and political process that demands more integrative response on community's social, cultural, and political structures and dynamics.
\end{abstract}

Keywords: Forest Management; Biodiversity Conservation; Social Forestry

\section{Introduction}

Establishment of Protected Areas (PAs) are primarily aimed at biological diversity conservation and provision of ecological services (Scherl et al., 2004). However, inclusion of the human dimensions in such initiatives has been raised. It is often a regulatory requirement to involve local communities in the establishment and management of PAs. For one, they are the major stakeholders in these areas. As Scherl et al. (2004:2) put it, their inclusion is based on "practical" and "ethical" considerations. The practical reason is that PAs could survive if they are considered as land-use options that help in pursuing sustainable development. The ethical consideration is based on the fact that "human rights and aspirations" are essential in "national and global strategies" for the attainment of social justice. The social dimension of PA establishments is legitimated by international agreements like the Convention of Biological Diversity and the Millenium Development Goals (Scherl et al., 2004).

Brechin et al. (2002:42) also considered "nature protection as a social and political process". Furthermore, Andrade and Rodes (2012) describe that failures to integrate social, cultural and political aspects into PA establishment negatively affect communities such as "disrupting their traditional ways of living and limiting their control of and access to natural resources". Hence, PA policies are undermined "through conflicts between park managers and local communities".

There are already a number of research articles and literature reviews about the relationship between human wellbeing and natural resources protection (Abukari and Mwalyosi, 2020; Naidoo et al., 2019; Nebasifu and Atong, 2019; Aryal and Ghimire, 2019; Bhattarai et al., 2017; Brockington and Wilkie, 2015; Woodhouse et al., 2015; Bottrill et al., 2014; Chowdhury and Koike, 2010; Mukul, 2007; Scherl, et al. 2004; Brechin et al., 2002). Many of these are quantitative studies examining the manifest or intended impacts of PAs on the well-being of local communities. The Literature Review will highlight some of these findings in more detail.

For the purposes of this paper, we extend discourses about the relationship between PAs and local communities by focusing on the latent functions and social consequences of PAs based on Robert Merton's Functional Analysis, which is a product of a qualitative study among selected stakeholders of Mount Hamiguitan, Davao Oriental, Philippines. It argues that there are latent 
functions and social consequences of PAs aside from intended and observable ones. While this paper does not conduct a holistic impact evaluation per se, it offers a thorough description on the perspectives or perceptions of selected stakeholders. Their narratives reveal PAs' consequences that offer useful inputs for improved biodiversity protection (Abukari et al., 2020). As this paper provides a deeper, sociological analysis on the social consequences of PAs, it responds to the call for measuring human well-being in a "holistic and locally grounded" manner in order to capture "multifaceted" impacts of conservation programs like PA establishment. This is a valid attempt that follows up on the challenge described by Bennett et al. (2016:93) in that social sciences are relevant in conservation initiatives for "descriptive, diagnostic, disruptive, reflexive, generative, innovative, or instrumental reasons". Indeed, it was argued that the "social sciences can help facilitate conservation policies, actions and outcomes that are more legitimate, salient, robust and effective."

\section{Literature Review: Impact of Protected Areas to Communities}

The literature shows a number of consequences of the establishment of PAs on communities. On the one hand, there are negative consequences, one of which are effects such as local displacement from their areas, often depriving access to key resources they may have depended on for their survival. Such conditions also result in pushing particularly the most marginalized communities further into poverty (Jacoby, 2001; Brockington and Igoe, 2006 cited in Brockington and Wilkie, 2015). From an anthropological perspective, West et al. (2006) presented a comprehensive review on the social, economic, and political effects of PAs. To name a few of these negative consequences, include altering land-use rights, displacing local people, causing conflicts, disrupting power and gender relations, changing how people see their relations with their environment, and the like. Andrade and Rodes (2012) also show that due to such disruptions in local traditional ways of living and constraints in their control and access to natural resources, conflicts between park managers and communities have taken place. Hence, environmental protection policies and other conservation initiatives are undermined. Even in PA co-management approaches there may also be issues and pitfalls. Based on a study in Bangladesh, for example, there are inconsistencies in policies such that some local initiatives are hampered by or clash with national provisions. There are also issues of unequal distribution of economic support, e.g. on the provision of livelihood projects, discrepancies between local residents, and issues whereby "local elites" usually control the benefits and decide the beneficiaries (Chowdhury and Koike, 2010).

PAs are also found less effective in dealing with deforestation, especially in tropical forest countries Porter-Bolland, et al. (2012:9). Torri (2011) argues that a top-down approach to forest management particularly in protected areas have been the common approach among states, and results to decisions that challenge the "livelihood and cultural heritage" of local communities. This management type of protected areas also failed to protect and conserve biodiversity for a variety of reasons. The restricted participation of the local people in management decisions limits their enhanced understanding of protected areas. Likewise, their dependence on the forest for their subsistence caused them to infringe on the PAs and extract resources, also leading to retaliations from state apparatuses like forest rangers (Torri, 2011).

The negative effects of ecotourism as an offshoot of PAs are also mentioned by West et al. (2006:262-263), and these include creating caricatures of local people and their environment, generating socioeconomic inequality due to inclusion and exclusion in PA management initiatives and their enterprises. There are also negative observable effects of ecotourism. In the Nepal experience, the increased number of tourists, resulted in excessive solid waste generation, as well as overexploitation of natural resources. Such problems are attributed to the absence of systematic management strategies (Bhattarai et al., 2017).

On the other hand, communities also benefit by establishment of PAs like providing new or enhanced livelihood opportunities, securing more formal rights in some cases, and also gain 
protection from more powerful external groups (Andam et al., 2010; Child, 2013; Dudley et al., 2011; Maekawa et al., 2013; Nelson et al. 2010 cited in Brockington and Wilkie, 2015). A survey conducted among local workers in Costa Rica revealed that the effect of PA on wages are on average, positive and significant although the magnitudes differ particularly in terms of proximity to the park. However, individual-level data showed that the positive effects might not be as large, especially for local and immigrant households (Robalino and Villalobos, 2015). The above finding is also contrasted by a study by Abukari et al. (2020) in which selected national parks in Tanzania and Ghana showed that communities adjacent to parks positively perceived the PA as it has impacts on their livelihoods and supports community development. A study on two national parks in Ghana also showed that community has positive attitudes towards PAs, attributed to participation in livelihood opportunities and other community development initiatives, also highlighting that PAs are likely to benefit from locally-tailored management interventions (Dewu, 2016).

In a strictly protected area, advocates contend that prohibiting extraction of resources supported with strong enforcement is a more effective approach to conservation. There is less deforestation in strictly protected areas as compared to non-protected areas provided that, there is success in the enforcement of forest regulations (Nolte et al., 2013). Community-managed approaches on the other hand, could also be successful considering the locations' propensities to deforestation (Nolte et.al, 2013). Community managed forests are found to have less deforestation but an investigation on institutional arrangements, particularly at the local level may be considered (Porter-Bolland et al., 2012). Allowing local communities, including local governments greater authority to manage conservation of natural resources can be advantageous in several ways. For one, they are more familiar with their own environmental problems, and thus, they could also think of more responsive interventions. Allocating resource management may also be easily organized and less costly. If the communities are involved in decision-making, they would more likely comply with conservation policies, and can be actively involved in localized monitoring systems with ease (Carney, 1995; Kaimowitz et al., 1998; Margulis, 1999 cited in Larson, 2003). Andrade and Rhodes (2012) mentioned that local community participation in PA decision-making process is related to level of compliance with PA regulations. Nebasifu and Atong (2019) added that systems of participation could be more feasible through explicit, accountable, and transparent open dialogue.

These assessments on the consequences of PAs in communities are valid inputs to approaches, initiatives, and legislations on forest protection for sustainable development. Many of these identified effects are manifest or intended while there could also be latent functions and unintended consequences, which could further describe the social dimension of PAs establishment. However, it would take qualitative inquiry to capture these realities. As Brockington and Wilkie (2015:4) suggested, "if we are to understand the issues of belonging, history, identity and security that are all integral to well-being, these will require more qualitative methods" as these could hardly be described by "positivist frameworks". More so, it takes a social scientists' perspective in providing such analysis. Hence, as Brechin et al. (2002:55) considered nature or forest protection as social and political processes, "social scientists could significantly add to debates on biodiversity conservation by addressing comprehensively the possible applications of their analyses and by pursuing greater cross-disciplinary collaboration".

\section{Theoretical Framework: Robert Merton's Functional Analysis}

This paper is anchored on the Functional Analysis of Robert Merton, an American Sociologist. Merton believed that any object that could be subjected to structural-functional analysis has to "represent standardized (patterned or repetitive) items such as "social roles, institutional patterns, social processes, cultural patterns, culturally patterned emotions, social norms, group organization, social structure, devices for social control, etc." He also argued that structural-functionalists have to focus on "social functions rather than individual motives". Hence, he defined functions as "those 
observed consequences which make for the adaptation or adjustment of a given system" (Merton,1949/1968:105 cited in Ritzer, 2011:253). Nevertheless, relating function to "system's adaptation or adjustment", may only assume for a social fact's positive consequences and ignore the tendencies for negative ones. Thus, Merton came up with the concept of "dysfunction" to refer to the social fact's negative consequences. He also suggested the concept of "net balance" to determine whether or not positive functions outweigh dysfunctions. However, there could be a problem on determining objectively the net balance since social realities are complex (Ritzer, 2011:253 \& 256).

Thus, Merton came up with levels of functional analysis. He suggested to consider the different social units (groups, organizations, institutions, etc.) in the analysis and juxtapose it with the positive and negative consequences of the social fact (actions or processes and structures) under investigation (Ritzer, 2011). More so, he found it important to distinguish the concepts of manifest and latent functions. Manifest functions are "functions whose utility is apparent" or observable or intended. Latent functions are functions that are "less apparent, perhaps unknown" to those who practice the action or hold the practice, which is beneficial to the whole of society or its various groups. However, such utility or positive consequence is not obvious nor observable and intended (Sharrock, Hughes and Martin, 2003:46; Ritzer, 2011).

Latent functions refer to those unintended functions of particular actions, practices, processes or structures. Such a concept is related to Merton's other concept of unanticipated consequences, which has three types: a) "those that are dysfunctional for a designated system, and these comprise the latent dysfunctions; b) those which are irrelevant to the system which they affect neither functionally or dysfunctionally or non-functional consequences; and c) latent functions, one that is functional for the designated system" (Merton, 1949/1968:105 cited in Ritzer, 2011).

While anyone would be able to recognize manifest functions or intended consequences of a particular practice, process or structure, "sociological analysis is required to uncover the unintended consequences... Peter Berger (1963) has called this "debunking," or looking beyond stated intentions to real effects" (Ritzer, 2011:256). Hence, it takes a sociological lens to unearth latent functions and other social consequences of a particular structure or practice like the establishment of PAs. Thus, anchored on this functional analysis of Merton, this paper attempts to uncover some latent functions and other social consequences of the establishment of Mount Hamiguitan, Philippines as a Protected Area and World Heritage Park.

\section{Methodology}

\subsection{Study Site}

Along with one of the bays often described as the most beautiful in the world named Pujada Bay, Mount Hamiguitan Range Wildlife Sanctuary (MHRWS) is located in Davao Oriental Province of the Philippines. The mountain has an elevation ranging from $170-1,637$ masl with a total ground delineated area of 7,132.76 hectares (figure 1), designating a total area of 6,348.99 hectares as its core zone and 783.77 hectares as a buffer zone (World Heritage Centre).

The mountain was declared as a Protected Area through Republic Act No. 9303 known as the Mt. Hamiguitan Range Wildlife Act of 2004 (The LawPhil Project, 2004). The declaration is in accordance with Republic Act No. 7586 or the National Integrated Protected Areas System (NIPAS) Act of 1992 which has been promulgated "to maintain essential ecological processes and lifesupport systems, to preserve genetic diversity, to ensure sustainable use of resources found therein, and to maintain their natural conditions to the greatest extent possible" (The LawPhil Project, 1992). The latter was expanded by Republic Act No. 11038 of 2018 or "An Act Declaring Protected Areas and Providing for Their Management, Amending for This Purpose Republic Act No. 7586, Otherwise Known as the "National Integrated Protected Areas System (NIPAS) Act of 1992" and for Other Purposes" (The LawPhil Project, 2018). 
In June 2014, prior to its ASEAN Heritage Park declaration, the Mount Hamiguitan Range Wildlife Sanctuary (MHRWS) was recognized by the UNESCO World Heritage Convention as having Outstanding Universal Value. The site was found to exhibit a combination of unique and interesting terrestrial and aquatic habitats that provides sanctuary to host threatened and endemic flora and fauna species only found in Mindanao, Philippines, Including the iconic Philippine Eagle, which nets on the mountain and several species of Nepenthes (World Heritage Centre).
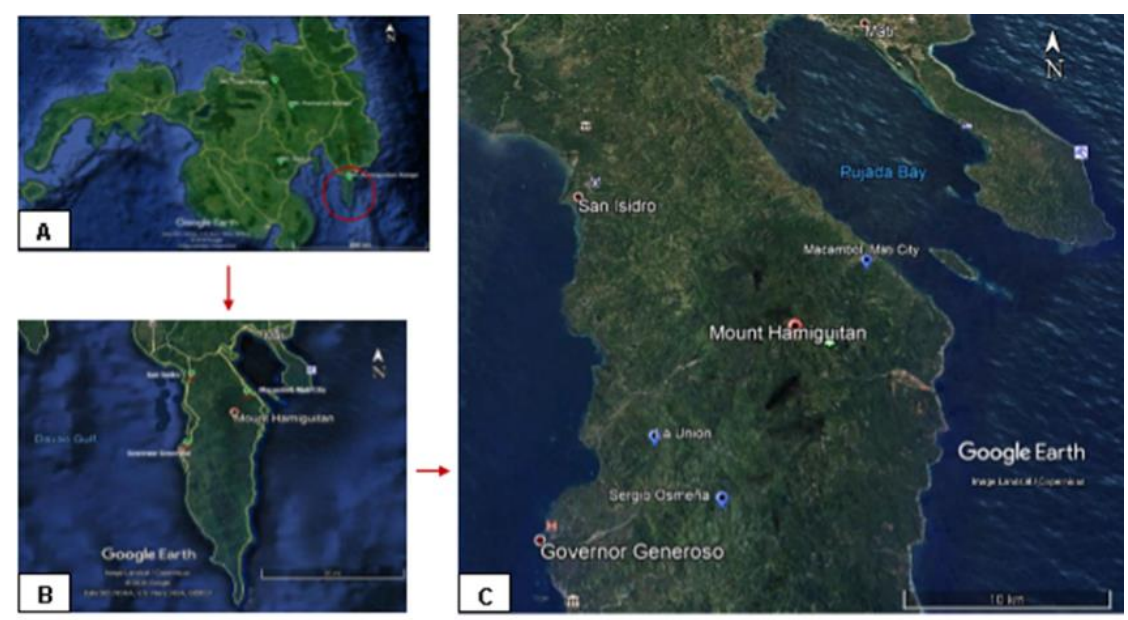

Figure 1. Map of Mindanao (A), Mt. Hamiguitan Range Wildlife Sanctuary (B) and (C) Barangay La Union, San Isidro, Barangay Sergio Osmeña, Governor Generoso and Baranagay Macambol, Mati City, Davao Oriental

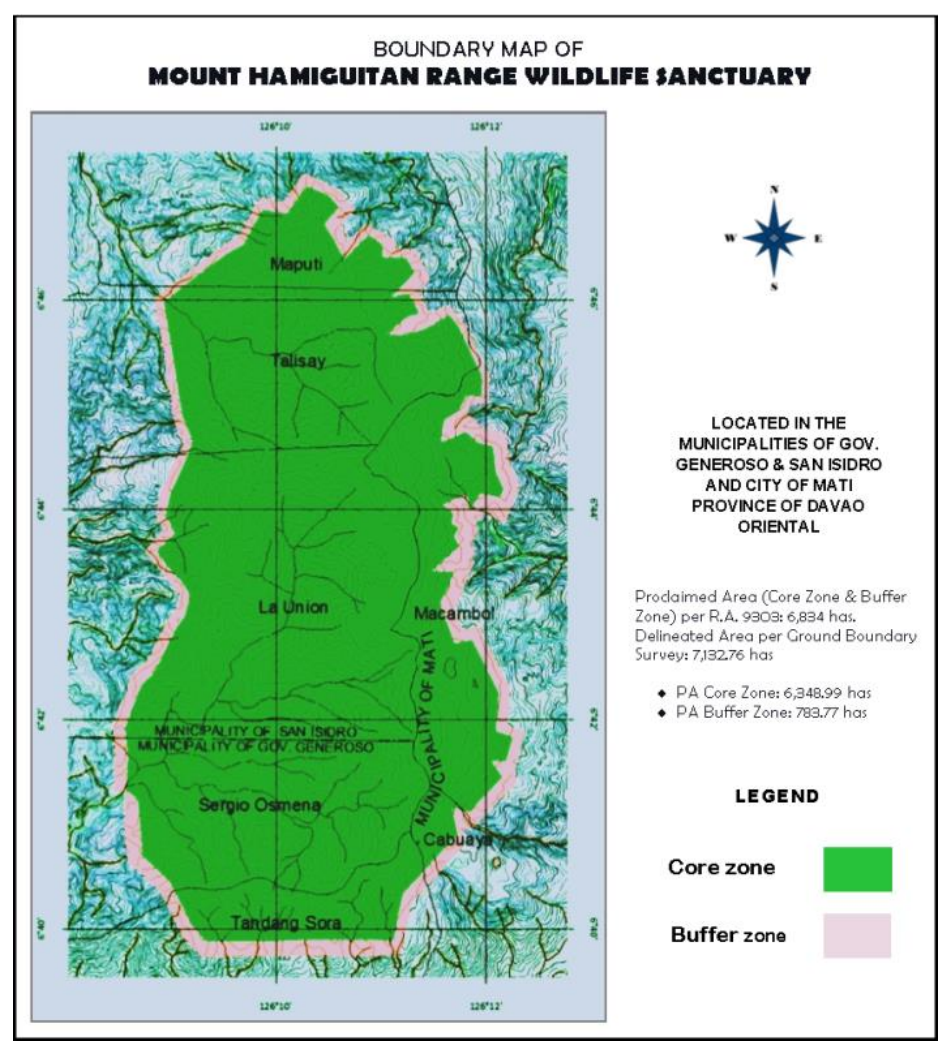

Figure 2. Delineated boundary map of Mt. Hamiguitan Range Wildlife Sanctuary, Davao Oriental, Philippines. Source: https://whc.unesco.org/en/list/1403/documents/ 


\subsection{Sampling, Data Gathering, and Data Analysis}

There were 21 key informants (KIs) purposely selected for interviews. The major criterion for selection is the informants' stake and direct involvement in the Range as PA. The Kls included Community Leaders like Barangay Captains/Chief Executive and Councilors, Indigenous Peoples leaders and elders, Forest guards/custodians, and Women's Organizations Leaders. The sample size was determined when "saturation" point, or the point when the responses were repetitive, was reached. Table 1 presents the socio-demographic characteristics of the KIs. This profile shows the heterogeneity of the informants and the challenges to capturing in-depth community experiences and perspectives on the consequences of the Mt. Hamiguitan Range. Specifically, the major thematic questions raised during the interviews include: 1) What are the changes in your community in the following areas, brought about by the proclamation of Mt. Hamiguitan as Protected Area and World heritage site? a) Social relations b) Economic conditions c) Biodiversity in the mountain; 2) How does the community respond to the said proclamation? Why? The data generated from the informants were then transcribed and analysed through Thematic Analysis. +

Table 1. Socio-demographic Profile of the KIs

\begin{tabular}{ccc}
\hline Variables & Frequency & Percentage \\
\hline Age & & \\
$30-45$ & 7 & 33.03 .00 \\
$46-60$ & 7 & 33.03 .00 \\
$61-75$ & 5 & 23.08 \\
76 -above & 2 & 09.06 \\
Total & $\mathbf{2 1}$ & $\mathbf{1 0 0 . 0 0 . 0 0}$ \\
\hline Sex & & \\
Female & 8 & 38.01 .00 \\
Male & 13 & 61.09 .00 \\
Total & 21 & 100.00 .00 \\
\hline Religion & & \\
Catholic & 16 & 76.02 .00 \\
Non-Catholic & 5 & 23.07 \\
Total & $\mathbf{2 1}$ & $\mathbf{1 0 0 . 0 0 . 0 0}$ \\
\hline Ethnicity & 12 & \\
Non-IPs & 7 & 57.01 .00 \\
Indigenous People (IPs) & 2 & 09.06 \\
Mixed & $\mathbf{2 1}$ & $\mathbf{1 0 0 . 0 0 . 0 0}$ \\
Total & & \\
\hline
\end{tabular}

\subsection{Research Ethics}

Prior to data gathering, Gratuitous Permit (GP), Memorandum of Understanding, and Institutional Ethics Research Committee's consent were secured. Other prescribed protocols were also observed to ensure that the research procedures are guided by the following elements of research ethics as stipulated in the "2017 National Ethical Guidelines for Health and Health-Related Research" (Philippine Health Research Ethics Board, 2017): Social Value, Informed Consent, Vulnerability of the Research Participants, Risk, Benefits, and Safety, Privacy and Confidentiality of Information, Justice, and Transparency. 


\section{Results and Discussion}

\subsection{Positive Latent Consequences: Benefitting the Communities}

The declaration of Mt. Hamiguitan as PA and UNESCO's World Heritage Site affected positively the communities by providing some opportunities for generating supplemental income, securing new resources, and preventing calamities.

However, aside from these manifest functions of PAs, the following themes demonstrate some latent functions of PAs in its surrounding communities. Following Merton's functional analysis, there are four latent functions of Mt. Hamiguitan as revealed in the experiences of the residents near the Park, namely: serving as a mechanism for social control, enhancing local awareness, forming associations, and enhancing credibility for tourism.

\subsubsection{Enhancing local awareness}

Another unintended function of PA declaration is that it has provided an opportunity for some of the locals to access more formal education opportunities. Additionally, more scientists and researchers conduct studies in the mountain, which employ and educate local guides. The local guides have the opportunity to learn new things and to be more sociable and confident while working with the scientists and experts. While the local guides are knowledgeable on the indigenous or local names and uses of plants and animals, they also appreciated the fact that they learn the scientific names based on morphology and location. A respondent related that, "...they did not know how to entertain before but now, they are so expert!...like the forest guards, they did not know the scientific names before, but now, they know the scientific names because of their interactions with researchers...".

Being able to enhance one's capacity could contribute to one's self-confidence and selfefficacy. Bandura (1995:2) referred to this as a perceived self-efficacy to "beliefs in one's capabilities to organize and execute the courses of action required to manage prospective situations". Thus, when these local guides develop their self-efficacy, they could have more opportunities to generate income. This effect of PA declaration was not anticipated but it offers opportunities for local communities by hiring them as local guides and later called as local "researchers".

More so, having the opportunity to enhance their level of environmental or ecological awareness, the locals may become more supportive of other initiatives related to biodiversity conservation and environmental protection. As mentioned by Sodhi et al. (2010), for more viable and sustainable PAs and other conservation initiatives, local people need to be provided with basic environmental education to strengthen their conservation support and alternative livelihood sources to reduce their dependence on the forest.

\subsubsection{Forming Associations}

The communities, particularly the forest guards, the local guides, and farmers, were mobilized upon the PA declaration. They are able to form associations in order to be organized in discharging their functions as PA stakeholders. In their association, the local guides are able to develop a system to organize their schedule, their compensation, and the like. The forest guards have also organized themselves in order to address issues and concerns collectively. As an association, they can facilitate trainings of others who would decide to become forest guards. The farmers are also organized so that their role, particularly in reforestation activities like tree planting, would be handled properly. Aside from men's farmer associations, there are also women's organizations in the area. These women's groups engage in projects that promote not only environmental protection (like tree planting) but also livelihood augmentation (selling seedlings, handicraft making, etc.). Unintentionally, the declaration of PA mobilizes its communities. 
The above findings may suggest that if properly guided, supported, and governed, these associations could become possible agents of positive changes and effective partners for sustainable development. Community mobilization could be easier if members are organized. Organizing people empowers communities to be able to affect change and deal with their issues and problems collectively (Brown, 2006). As mentioned by Pretty and Smith (2004), local groups and associations affected "positive biodiversity outcomes" as "social connectedness" brings in social capital which is essential to "collective management programs" including establishment of PAs. Likewise, Magno (2001) argued that social capital enhances "local participation and capacity in forest governance". Bonding social capital was seen as a determinant in the success of managing resources as evident in the case of Kalahan Educational Foundation, Philippines (Dahal and Adhikari, 2008). In the study of Cagalanan (2013), in Northern Negros Natural Park, Philippines, it was also suggested that maximizing stakeholder participation in the Park's management is one of the possible ways to reduce deforestation. Finally, local community participation in the PA decision-making process was found significant in affecting the level of compliance with PA- related policies (Andrade and Rhodes, 2012).

\subsubsection{Enhancing credibility for tourism}

Prior to the PA declaration, there were already tourists visiting the area because of its unique scenery as a mountain and for its natural resource vistas. However, the declaration enhanced the credibility of the area for tourism thus increasing the number of tourists. As narrated by a resident, "...there is a big difference ma'am because before, if you do not have a picture to show to the visitor, they would not go/climb, but now, even if there are no pictures, if they could just hear the testimonies of others who visited, they would really go/climb...". This narrative explains that the declaration of Mount Hamiguitan as a Protected Area and as a World Heritage Site had facilitated the increase in the number of tourists in the area. Such increase in the number of tourists is viewed positively by some members of the community especially by the local guides. Each local guide is able to generate income amounting to about 500.00 pesos (approximately $10 \$$ ) per day , from guiding and helping the tourists carry their things to the mountain.

Despite the negative social consequences of tourism as mentioned by West et al. (2006) and Bhattarai et al. (2017), ecotourism is one of the common strategies for sustainable development considered by many local government units (LGUs), at least in the Philippines. However, the government needs to play a crucial role in ecotourism. As suggested by Aryal and Bina (2019), government has to determine the "carrying capacity and environmental implication" and not just focus on increasing the number of tourists. It has to formulate specific tourism and conservation policies. Badola et al. (2018) also recommended that "in natural landscapes with conflicting interests among stakeholders, a hierarchical three-tier institutional arrangement should be encouraged to achieve the goals of sustainable tourism".

Indeed, the abovementioned unintended consequences of PA declaration may bring positive impacts on its communities especially when these are accurately translated into more concrete initiatives. However, the said declaration has also resulted to certain community responses that may explain some failures in such protection and conservation efforts. Using a sociological lens, there are socio-political and cultural factors which resulted in non-compliance to some protection and conservation regulations. As presented in the following section, these reasons for limiting positive results of the PA declaration include fearing threats and ruined relationships with neighbors and relatives, holding on to traditional subsistence pattern, receiving limited sanctions, weakening influence of authorities, and lacking intensive and systematic monitoring.

\subsection{Community Responses: Failing forest protection initiatives}

In the implementation of forest protection initiatives like recruitment of forest guards, and passing of legislations on the prohibition of logging, hunting, collecting endangered plants, and 
mining in the area, there are community responses that limit PA's success. Deforestation activities in the PA persist despite such initiatives. The following responses of the community demonstrate subtle and unexpected reasons for their non-compliance to forest protection initiatives.

\subsubsection{Fearing threats and ruined relationships}

Forest guards and community representatives are discouraged to continue with their protection activities because they receive threats from people who are either residents or nonresidents in the area. A respondent shared that he opted to stop from being a forest guard because he was afraid after receiving a threat that he might be killed. According to him, "...I hear statements like, there would really be a body to be 'smelled' (or killed) at the forest".

The forest guards are also afraid of ruining the relationship with their neighbors. They opted not to report to the concerned authority like the Department of Environment and Natural Resources (DENR). As revealed by a forest guard, "...l am hesitant to report (to the authority) because those who cut trees are our neighbors, so I decided to quit (being a forest guard) because it is so hard to make them our enemy...".

Likewise, the forest guards are hesitant to report (to the authorities) the illegal loggers who are their neighbors because they feel pity for them. Once they caught their neighbors, they would just ask the latter to stop cutting trees and remind them of the consequences of their action. For those who continue to cut trees, they revealed that they also understood the motivations of their neighbors because of their needs. The latter could get an income from cutting trees which they sell usually at furniture shops in their town or at a neighbor who plans to build a house. As mentioned by one of the respondents, "...For those who do not abide (with the policy), we also understand because we know how poor they are and how many mouths could eat for cutting even just one tree..."

The above narratives demonstrate the communities' value of life and relationships especially with kin, friends, and neighbors. They do not want to lose their ties with whom they could also get some support especially in times of crisis. However, this situation may pose a dilemma in the context of implementation of the PA regulations.

\subsubsection{Holding on to traditional subsistence pattern}

Despite prohibitions, some of the community residents continue to cultivate, cut trees, and hunt animals in PAs because culturally, these activities had been part of their traditional practices. They may have some limited options for other means of livelihoods but they hold on to such traditional means of living. As shared by one of the community leaders, "...they have been used to those means of livelihoods in the past because before it was not yet protected, and that was their source of food/viand...".

It is clearly stated in the guidelines of the PA declaration that such acts as hunting of animals, cutting, gathering or collecting timber or other forest products without a license is strictly prohibited (The LawPhil Project, 2004). However, aside from the economic reasons for continuously encroaching the forest, their culture influences them to have such subsistence patterns. The indigenous peoples (IPs) have considered the forest not only as their source of food but also of medicines.

Traditionally, there are three concepts to describe how the IPs regard the forest namely: sacred, sanction, and selective. The IPs regarded the mountain/forest as a sacred place. They believe that it is owned by God and that spirits inhabit the forest including the trees, rocks, and creeks. Since the forest is considered as sacred, owned by God, and spirits inhabit all its resources, they believed that whenever they enter the area, they have to ask permission by conducting a ritual for their protection, for a catch when they hunt, and for effective cure of diseases using the plants that they collected from the forest. 
The second concept is sanction which could be related to the first. The IPs believe that if they would not respect the spirits in mountain/forest by not conducting rituals, they would be harmed and sanctioned.

The third and last concept is selective. The IPs identified certain area in the forest that should not be "touched". In other words, no hunting of animals, no cutting of trees, no collection of plants, and no clearing for farming are allowed. They also identified certain part of the creeks where catching of fish is prohibited. Also, in fishing, their strategy is to drain a certain area so that they could choose the big ones and discriminate the small ones. After the selection, they would irrigate again the area.

While the above practices were most likely held by their elders, the informants believed that these indigenous ways somehow influenced them in their regard of the forest. These indigenous practices demonstrate a protective and conservationist way of using the forest and its resources.

\subsubsection{Receiving limited sanctions}

Many of the residents recognized that one of the reasons for continued illegal logging is the fact that suspects receive minimum sanction. As narrated by some residents, "...they are not imprisoned, (the authorities) only file a case against them, their lumber/wood (taken from the forest) will be confiscated...they would not allow themselves to be caught because only the wood and their units (like chainsaw) are taken...".

The above narrative shows that from the perspective of the community, the sanction imposed for those who extract trees/timber illegally from the forest is too limited. In this case, Durkheim, may be right in considering the regulation or "the degree of external constraint on people" determines one's conformity with the norms or laws (Ritzer, 2011). Hence, this limited sanction contributes to non-compliance with the regulation on extracting resources from the PA. Providing limited sanction is also supported by weakening influence of authorities, and lacking intensive and systematic monitoring, which are discussed below.

The above experience in Mount Hamiguitan could be related to the study of Dahal and Capistrano (2006) on the devolution process of forest management in the Philippines. There were identified strategic weaknesses of the process namely "inadequate policy articulation and a set of differences between policy and complex reality implementation". As also mentioned by Van der Ploeg et al. (2011), there is a need to strengthen law enforcement in order to achieve a more sustainable forest management within and the vicinity of PAs in Southeast Asia.

\subsubsection{Weakening of authorities' influence}

Less respect to the authorities is evident in Mt. Hamiguitan as cutting of trees persists in the area. According to one of the community leaders, "...the "illegalists" are watchful of the law enforcers, if they (enforcers) are no longer around, they (illegalists) would climb the mountain...". A forest guard also related, "...that is the system in the mountain, while we are watching over them, they also watch over us, they are even the first to hide...".

It is a challenge on the part of the enforcers of policies in the PA, to address the above issue. Disrespect to authority may just be a secondary reason to the need for source of income and livelihood. However, if it would be dealt with properly, implementation of PA regulations could still succeed. Thus, PA implementers and enforcers may try to reconsider how the communities perceive them. This would entail deliberate consultations and dialogues with the latter. As Brechin et al. (2002) argued, further "clarification and constructive debate" is essential to safeguard and sustain biodiversity. This contention is especially necessary in the case of an "authoritarian protectionist approach" otherwise, policies could become "morally and pragmatically questionable". Similarly, in a study of three Natural PAs in the Yucatan Peninsula, it was revealed that there are common difficulties in terms of Mexican PA policy. These issues include: "(1) uncoordinated public policies; (2) the usual conflict between environmental authorities and local people over the management of 
natural resources; and (3) the exclusion of local people's perspectives, values and beliefs in conservation policy development and implementation" (García-Frapolli et al., 2009).

Thus, while the need for income primarily drives these illegal tree cutters in Mount Hamiguitan, they might be controlled if protection regulations are clearly communicated to them. Their negative perception and disrespect towards the authorities may be changed when they are consulted. Such consultation also facilitates understanding on the conditions of these communities by the authorities themselves.

\subsubsection{Lacking intensive and systematic monitoring}

The residents recognized the importance of the declaration of Mt. Hamiguitan as PA and a World Heritage Site. However, they are worried that these efforts on forest protection could not be sustained for lack of intensive monitoring, particularly due to intensive human impact. One forest guard even shared a figurative statement and compared it to corn being dried on a dryer. He said that, "For example, if you dry a corn and the chicken will pick it, you could not get rid of them because there is no more system there...". This statement means that a sustained monitoring in the area has to be established otherwise, illegal cutters would continue to encroach the forest.

Substituting the intensive role of forest guards in the mountain with the use of CCTV camera alone is being attributed (by some forest guards) as one of the reasons for continued illegal cutting of trees. Having forest guards inside the PA could inhibit illegal loggers to enter an area. They argued that, "...previously, when there were forest guards assigned inside the PA,...the illegal loggers could not easily get in... we really kept on moving around the mountain (before), then we put up our camp where we settled after moving around ...".

The use of cameras alone were found less effective than having the forest guards in the area. One argued, "...they only use camera traps but for me, it is not effective because humans are more intelligent than cameras. They could easily get rid of the camera but it is useless because you can redirect yourself away from the camera. It is really different if there are people who guard and monitor the forest..."

It is evident in the above narratives that communities recognize the need for concrete and sustained mechanisms to monitor PA protection and conservation. There seems to be a lag between the communities' understanding on the use of modern technology like a camera, and its intended uses. Thus, educating and building capacity is necessary. Most importantly, their fear of becoming displaced has to be addressed since this technology is intended to monitor wildlife but not to replace forest guards.

\section{Conclusion}

This paper argues that there are latent functions and social consequences of PAs other than the intended and manifested ones. PA's establishment has positive latent consequences include enhancing local awareness, forming associations, and enhancing credibility for tourism. Together, these show a PA's contribution to the community, particularly in its social dimensions. Likewise, these consequences demonstrate that PAs could hardly be dissociated from its local community. Hence, PA policies and programs have to be in synergy with the people and local communities. These consequences also signal the potential of communities to become instrumental to the success of PAs. They could be effective partners for more sustainable biodiversity conservation. However, the challenge is how to actualize this partnership as there are also impeding internal and external factors in these communities.

The community responses which could be attributed to a failure of some protection and conservation initiatives include: fearing threats and ruined relationships, holding on to traditional subsistence patterns, receiving limited sanctions, weakening of authorities' influence, and lacking 
intensive and systematic monitoring. These reflect that PA establishment is a complex social and political process. These responses also imply that the continuous encroachment in the forest and extraction of its resources are beyond economic survival. There are also social, cultural, and political conditions that undermine conservation efforts. These realities could be manifested in varying degrees and forms in different contexts. Thus, it would require a more complex, integrated, and well-planned conservation agenda for a specific context.

While this paper is limited to community perspectives of a particular context in the Philippines, it contributes to the discourse on forest protection and biodiversity conservation. Specifically, this paper has explored the dynamics of communities affected by the establishment of protected areas. Hence, there is also a need to further examine the dynamics and issues relative to the implementation processes and the implementing bodies, at least in the context of the Philippines or other countries that have a similar context.

Competing interests: The authors declare no conflict of interest. The authors declare that they have no known competing financial interests or personal relationships that could have appeared to influence the work reported in this paper.

\section{Acknowledgments}

The authors are grateful to the Department of Science and Technology (DOST) of the Republic of the Philippines (RoP) for funding this study. They are also thankful to their institutions, the Central Mindanao University and the Davao Oriental State College, for the administrative and logistic support. Finally, they thank the informants and participants of this research for voluntarily sharing their time and experiences.

\section{References}

Abukari, H., \& Mwalyosi, R. B. (2020). Local communities' perceptions about the impact of protected areas on livelihoods and community development. Global Ecology and Conservation, 22, e00909. doi: https://doi.org/10.1016/j.gecco.2020.e00909

Aryal, C., Ghimire, B., \& Niraula, N. (2019). Tourism in protected areas and appraisal of ecotourism in Nepalese policies. Journal of Tourism and Hospitality Education, 9, 40-73. doi: https://doi.org/10.3126/jthe.v9i0.23680

Andrade, G. S., \& Rhodes, J. R. (2012). Protected areas and local communities: an inevitable partnership toward successful conservation strategies?. Ecology and Society, 17(4). doi: http://dx.doi.org/10.5751/ES-05216-170414

Badola, R., Hussain, S. A., Dobriyal, P., Manral, U., Barthwal, S., Rastogi, A., \& Gill, A. K. (2018). Institutional arrangements for managing tourism in the Indian Himalayan protected areas. Tourism Management, 66, 1-12.doi: https://doi.org/10.1016/j.tourman.2017.10.020

Bandura, A. (Ed.). (1995). Self-efficacy in changing societies. Cambridge university press. Retrieved from www.cambridge.org/9780521474672 doi: https://doi.org/10.1017/CBO9780511527692

Bennett, N. J., Roth, R., Klain, S. C., Chan, K., Christie, P., Clark, D. A., Cullman, G., Curran, D., Durbin, T.J., Epstein, G., Greenberg, A., Nelson, M.P., Sandlos, J., Stedman, R., Teel, T.L., Thomas, R., Veríssimo, D., Wyborn, C. (2016). Conservation social science: Understanding and integrating human dimensions to improve conservation. Biological Conservation, 205, 93108. doi: http://dx.doi.org/10.1016/j.biocon.2016.10.006

Bhattarai, B. R., Wright, W., Poudel, B. S., Aryal, A., Yadav, B. P., \& Wagle, R. (2017). Shifting paradigms for Nepal's protected areas: history, challenges and relationships. Journal of Mountain Science, 14(5), 964-979. doi: https://doi.org/10.1007/s11629-016-3980-9

Bottrill, M., Cheng, S., Garside, R., Wongbusarakum, S., Roe, D., Holland, M. B., ... \& Turner, W. R. (2014). What are the impacts of nature conservation interventions on human well-being: a 
systematic map protocol. Environmental Evidence, 3(1), 1-11. doi: https://doi.org/10.1186/2047-2382-3-16

Brechin, S. R., Wilshusen, P. R., Fortwangler, C. L., \& West, P. C. (2002). Beyond the square wheel: toward a more comprehensive understanding of biodiversity conservation as social and political process. Society \& Natural Resources, 15(1), 41-64. doi: https://doi.org/10.1080/089419202317174011

Brockington, D., \& Wilkie, D. (2015). Protected areas and poverty. Philosophical Transactions of the Royal Society B: Biological Sciences, 370(1681), 20140271. doi: http://dx.doi.org/10.1098/rstb.2014.0271

Brown, M. J. (2006). Building powerful community organizations. Arlington, MA: Long Haul. doi: https://doi.org/10.1080/10705420801978070

Chowdhury, M. S. H., \& Koike, M. (2010). An overview on the protected area system for forest conservation in Bangladesh. Journal of Forestry research, 21(1), 111-118. doi: http://dx.doi.org/10.1007/s11676-010-0019-x

Dahal, G. R., \& Adhikari, K. P. (2008). Bridging, linking, and bonding social capital in collective action: The case of Kalahan Forest Reserve in the Philippines (No. 577-2016-39220). doi: 10.22004/ag.econ.44352

Dewu, S. (2016). Fringe Community Attitudes and Protected Areas.-Insights from two Protected Areas in Ghana (Master's thesis, NTNU).

García-Frapolli, E., Ramos-Fernández, G., Galicia, E., \& Serrano, A. (2009). The complex reality of biodiversity conservation through Natural Protected Area policy: three cases from the Yucatan Peninsula, Mexico. Land Use Policy, 26(3), 715-722. doi: https://doi.org/10.1016/j.landusepol.2008.09.008

Larson, A. M. (2003). Decentralisation and forest management in Latin America: Towards a working model. Public administration and development,23(3), 211-226. doi: http://dx.doi.org/10.1002/pad.271

Magno, F. (2001). Forest devolution and social capital: State-civil society relations in the Philippines. Environmental History, 264-286. doi: https://doi.org/10.2307/3985087

Mukul, S. A. (2007). Biodiversity conservation strategies in Bangladesh: the state of protected areas. Tigerpaper, 34(3), 28-32.

Naidoo, R., Gerkey, D., Hole, D., Pfaff, A., Ellis, A. M., Golden, C. D., Herrera, D.., Johnson, K., Mulligan, M., Ricketts, T.H., \& Fisher, B. (2019). Evaluating the impacts of protected areas on human well-being across the developing world. Science Advances, 5(4), eaav3006. doi: http://dx.doi.org/10.1126/sciadv.aav3006

Nebasifu, Ayonghe Akonwi \& Ngoindong Majory Atong (2019). Rethinking Institutional Knowledge for Community Participation in Co-Management Sustainability. 11, 5788; doi:10.3390/su11205788

Nolte, C., Agrawal, A., Silvius, K. M., \& Soares-Filho, B. S. (2013). Governance regime and location influence avoided deforestation success of protected areas in the Brazilian Amazon. Proceedings of the National Academy of Sciences, 110(13), 4956-4961.doi: https://doi.org/10.1073/pnas.1214786110

Philippine Health Research Ethics Board (2017). National Ethical Guidelines for Health and HealthRelated Research. Department of Science and Technology - Philippine Council for Health Research and Development, Philippines.

Van der Ploeg, J., Van Weerd, M., Masipiqueña, A., \& Persoon, G. (2011). Illegal Logging in the Northern Sierra Madre Natural Park, the Philippines. Conservation and Society, 9(3), 202-215. Retrieved November 17, 2020, from http://www.jstor.org/stable/26393043 DOI: 10.4103/0972-4923.86991 
Porter-Bolland, L., Ellis, E. A., Guariguata, M. R., Ruiz-Mallén, I., Negrete-Yankelevich, S., \& ReyesGarcía, V. (2012). Community managed forests and forest protected areas: An assessment of their conservation effectiveness across the tropics. Forest ecology and management, 268, 617. doi: https://doi.org/10.1016/j.foreco.2011.05.034

Pretty, J., \& Smith, D. (2004). Social capital in biodiversity conservation and management. Conservation biology, 18(3), 631-638. doi: http://dx.doi.org/10.1111/j.15231739.2004.00126.x

Ritzer, G. (2011). Sociological Theory. $8^{\text {th }}$ ed. USA: The McGraw-Hill Companies, Inc.

Robalino, J., \& Villalobos, L. (2015). Protected areas and economic welfare: an impact evaluation of national parks on local workers' wages in Costa Rica. Environment and Development Economics, 20(3), 283-310. doi: http://dx.doi.org/10.1017/S1355770X14000461

Sharrock, W., Hughes, J. A., Martin, P. J., \& Pratt, A. (2003). Understanding modern sociology. Sage. Scherl, L. M., Wild, R., \& Wilson, A. (2004). Can protected areas contribute to poverty reduction?: opportunities and limitations. IUCN. Retrieved from: http://lib.riskreductionafrica.org/bitstream/handle/123456789/281/5672\%20\%20Can\%20Pr otected\%20Areas\%20Contribute\%20to\%20Poverty\%20Reduction.\%200pportunities\%20and $\% 20$ Limitations.pdf?sequence $=1$ \&isAllowed $=y$

Sodhi, N. S., Lee, T. M., Sekercioglu, C. H., Webb, E. L., Prawiradilaga, D. M., Lohman, D. J., Pierce, N.E., Diesmos, A.C., Rao, M., \& Ehrlich, P. R. (2010). Local people value environmental services provided by forested parks. Biodiversity and Conservation, 19(4), 1175-1188. doi: http://dx.doi.org/10.1007/s10531-009-9745-9

Torri, M. C. (2011). Conservation, relocation and the social consequences of conservation policies in protected areas: Case study of the Sariska Tiger Reserve, India. Conservation and Society, 9(1), 54-64. Retrieved November 17, 2020, from http://www.jstor.org/stable/26393125 DOI: 10.4103/0972-4923.79190

The LawPhil Project, (2018). Retreived from https://www.lawphil.net/statutes/repacts/ra2018/ra_11038_2018.html

The LawPhil Project, (2004). Retreived from https://lawphil.net/statutes/repacts/ra2004/ra_9303_2004.html

The LawPhil Project, (1992). Retreived from https://lawphil.net/statutes/repacts/ra1992/ra_7586_1992.html

West, P., Igoe, J., \& Brockington, D. (2006). Parks and peoples: the social impact of protected areas. Annu. Rev. Anthropol., 35, 251-277. doi: http://dx.doi.org/10.1146/annurev.anthro.35.081705.123308

Woodhouse, E., Homewood, K. M., Beauchamp, E., Clements, T., McCabe, J. T., Wilkie, D., \& MilnerGulland, E. J. (2015). Guiding principles for evaluating the impacts of conservation interventions on human well-being. Philosophical Transactions of the Royal Society B: Biological Sciences, 370(1681), 20150103. doi: http://dx.doi.org/10.1098/rstb.2015.0103

World Heritage Centre. Retrieved September 08, 2020, from World Heritage Centre https://whc.unesco.org/en/list/1403/documents/ 